\title{
Evaluating socio-economic and environmental factors influencing farm-level water scarcity in Punjab, Pakistan
}

\author{
M. Awais Ali Khan ${ }^{1 *}$, Khalid Mahmood Ch. ${ }^{1}$, Ijaz Ashraf ${ }^{1}$, Muhammad Tahir Siddiqui ${ }^{2}$ \\ and Jerry W. Knox ${ }^{3}$ \\ ${ }^{1}$ Institute of Agricultural Extension and Rural Development, UAF, Pakistan \\ ${ }^{2}$ Dept. of Forestry and Range Management, University of Agriculture, Faisalabad, Pakistan \\ ${ }^{3}$ Cranfield University, Cranfield, Bedford MK43 OAL, UK \\ *Corresponding author: m.awais925@gmail.com
}

\begin{abstract}
Pakistan's economy is primarily dependent on agriculture, but it faces serious water challenges. This paper critically evaluates the water resources, socio-economic and environmental factors contributing to increased farm-level water scarcity in the Punjab region. The study involved conducting structured interviews with 370 farmers to gather data necessary for conducting a detailed socio-technical factor analysis. From this, eight factors were identified that were found to directly impact on farmer wellbeing including climate change, poor socio-economic farmer conditions, issues linked to the warabandi (canal water distribution system), inadequate irrigation, reduced water availability, poor water course maintenance and low adoption of efficient irrigation techniques. The Kruskal Wallis Test was then used to assess statistical differences between the respondent's demographic attributes and the identified factors. Demographic factors including age, education, land size, farming experience and cultivated area showed significant mean differences with the eight factors. Young farmers with higher education levels were more likely to adopt high efficiency irrigation systems to conserve water. The research also highlighted the importance of introducing lower water demanding crops into the region, and the need to proactively support agricultural extension services to encourage farmers to adopt more efficient irrigation systems to improve crop productivity and facilitate on-farm water conservation.
\end{abstract}

Keywords: agriculture; climate change; drought; irrigation; water resources 


\section{Introduction}

In Pakistan agriculture contributes nearly a fifth (18.9\%) to the country's gross domestic product (GDP) and employs nearly half (42.3\%) the national labour force. However, an increasing population is exerting severe pressure on the need to increase agricultural productivity. Crop diversification, more efficient use of water, the promotion of high-value crops, enhancing the availability of agricultural credits, the provision of subsidised inputs and support for technical advisory services are key priorities that have recently been identified to improve the agricultural sector (Government of Pakistan, 2019). Awan and Mustafa (2013) reported that a $1 \%$ increase in water availability would increase agricultural growth by $0.93 \%$ in Pakistan. Conversely, agricultural production is known to be negatively impacted by any reductions in water availability. Reliable supplies of water for agriculture are essential therefore to support sustainable development. Agriculture is the largest consumer $(>90 \%)$ of water in Pakistan with timely supplies of water critical since $90 \%$ of food comes from irrigated production, with only 10\% from dryland agriculture (Qureshi, 2019).

Pakistan has an extensive irrigation system on which almost the entire agricultural sector is dependent; this is often referred to as the Indus Basin Irrigation System (IBIS) and is reported to have the largest irrigation command globally. The IBIS covers almost $65 \%$ of Pakistan, with 20\% in China and Indian Occupied Kashmir, 7\% in Azad Kashmir and 8\% in Afghanistan (Burki, and Laporte 1984). In Pakistan, it is located in the mountainous areas north and west to the Indus and Kacchi plains and the desert of the Sindh and Balochistan. The Indus, Jhelum, Kabul and Chenab rivers flow from the Indus basin with Pakistan having rights on these four river systems to acquire water for irrigation. The total catchment area of the Indus river system is 364,700 miles $^{2}$. From this, an annual withdrawal of 141.67 millionacre feet (MAF) comes from this basin (Shahzad, 2016), with 104.72 MAF diverted for irrigated agriculture. The IBIS is $2900 \mathrm{~km}$ long, has a drainage area of $966,000 \mathrm{~km}^{2}$ and is comprised of three main types of canals including perennial, non-perennial and inundation. Snow and glacial melt and rainfall in the region are the main sources of water for the IBIS. Other than the IBIS, most of the rivers in Pakistan are ephemeral, and only flow during the rainy season. Therefore, these rivers do not contribute to the water needs of the IBIS inside the basin (Qureshi, 2011). Pakistan relies on both natural and stored water resources. Natural resources include rainfall, rivers, ponds, lakes and glaciers and storage within the IBIS. The monsoon and western depression (a weather system, which originates over the Mediterranean Sea) are two major sources of rainfall. Pakistan receives about $70 \%$ of annual monsoon rainfall between July and September. The entire Indus plain receives an average rainfall of $212 \mathrm{~mm}$ and $53 \mathrm{~mm}$ in the Kharif (summer) and Rabi (winter) cropping seasons, respectively (Ahmed et al., 2007).

In Pakistan, over-irrigation is responsible for wasting a significant volume of water which has resulted in problems linked to nutrient leaching and soil erosion (Kaleem, 2004). In 1951, per capita water availability was reported to be $5,600 \mathrm{~m}^{3}$; now it is currently less than $1000 \mathrm{~m}^{3}$ (Awan and Mustafa, 2013; Lohano and Marri, 2020). A changing climate coupled with a rising population and mis-management of water resources are the main reasons of fluctuations in water availability (Shahzad, 2016). Better management of water resources as well as an improved farmer education regarding the importance of water and its conservation is thus urgently needed.

Whilst numerous studies in Pakistan have evaluated water resource availability and water conservation for agriculture, much fewer studies have specifically evaluated the factors impacting on-farm that contribute to agricultural water scarcity. The aim of this study therefore was to critically analyze these environmental and socio-economic aspects that are 
contributing to increased water scarcity at farm-level using principal component analysis techniques which are part of the boarder domain of factor analysis.

\section{Methodology}

The research was targeted in the Punjab region which was selected through purposive sampling on the basis of having the largest provincial population and a high dependence on water to support irrigated cultivation (Figure 1). The Punjab has an area of 50.9 million acres, of which $54 \%$ is cultivated. This extensive area requires a substantial amount of irrigation (Alam et al, 2000). The study was conducted within Faisalabad district, which was selected through lottery method of sample selection. The Punjab province comprises 36 districts tickets bearing each district name were prepared. One ticket was chosen; this was Faisalabad. This lottery method gave each district an equal chance of selection and has been used in previous studies (Thakur, 2003; Hassan, 2007). Faisalabad is known for its agricultural potential and the Lower Chenab Canal (LCC) which is the main source of irrigation used for supplying $80 \%$ of cultivated land in the district. The most common method is surface or flood irrigation in the study area. The soils in the region are mainly loamy with a significant proportion of silt (Ahmad and Rasul, 2008). The major crops in the study area were wheat, sugarcane, corn and fodder.

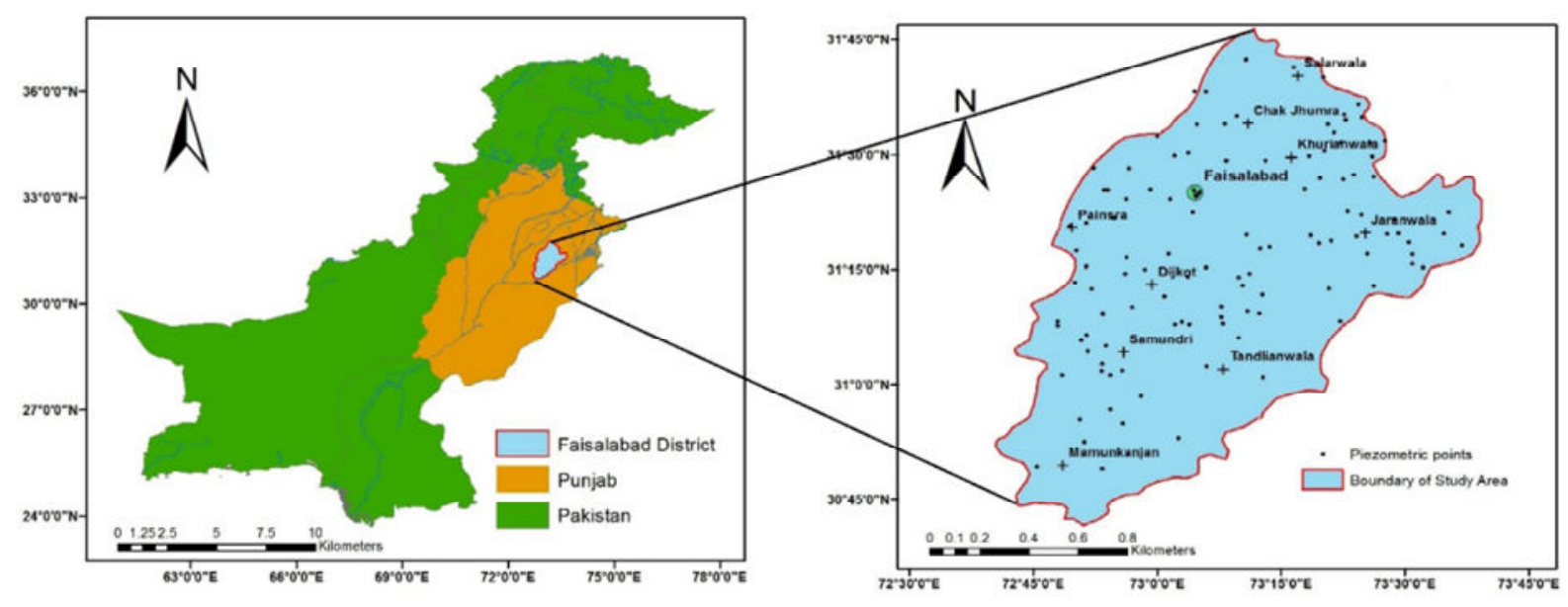

Figure 1: Map of Pakistan showing the Faisalabad study area located within the Punjab region.

The LCC contains the Rakh Branch, Jhang Branch (Upper), Jhang Branch (Lower), Gogera Branch and Bhowana Branch Canals. Through purposive sampling the Rakh branch canal was selected on the basis of having the largest irrigated area comprising of 32 distributaries and 346 outlets. There were reported to be 32667 farmers who received direct benefits from the canal water (Asghar, 2014). From the 32 distributaries, the Butti, Dijkot, Lakhuana and Taror were purposively selected as compared to the other distributaries these have a larger number of beneficiary farmers. Using surveysystem.com a sample of 370 farmers were selected from the total farmer population (32667). Proportionate sampling technique was adopted for each distributary, resulting in 60 farmers selected from Butti, 178 from Dijkot, 76 from Lakhuana and 53 from the Taror distributary. An equal number of farmers were selected from the head, middle and tailwater sections of the distribution canal. An interview schedule was then designed to collect data from the respondents, drawing on previous research. Potential factors linked to water scarcity were identified and incorporated into the research instrument through a review of literature, and a variety of questions defined using different options including the Likert scale, open-ended and close-ended questions, funnel and inverted funnel questions. 
Using a range of different types of question can help in collecting meaningful and result oriented data (Ponto, 2015). The interview schedule was pre-tested with 40 farmers to check the reliability of the research instrument. Minor revisions were made to the interview schedule. The reliability of the interview schedule was assessed using the Cronbach Alpha technique; a value of 0.85 for the data from the 40 respondents confirmed that the research tool was reliable. Quantitative data from 370 respondents were then collected through face-toface interviews to ensure the reliability of the data. Data collection was undertaken over a period of 8 months in 2019. Data were analysed using the Statistical Package for Social Sciences (SPSS); in addition, descriptive analysis techniques were used to assess the relationships between the demographic attributes of the respondents with the newly extracted factors.

Principal component analysis (PCA) was then used to identify the factors influencing farm level water scarcity. PCA is a multivariate statistical technique that is widely used to identify critical components in a study. The method is guided by central data or its differences and particularly used to explore forms of concurrent variation (Wang et al., 2014). PCA was used to reduce the larger data sets, engaging many inter-related variables into smaller data sets which are easy to handle unrelated variables. The outcome variables maintain the existing variability of the original datasets intact. These variables are grouped linearly, and the eigenvector values denoted coefficients. Each variable back total variance of the original values. Each variable contributes to the total explained variance of the original variables. One main advantage is that PCA can uniquely identify key variables from overlapping variables (Kumar and Chand, 2004) by reducing the large set of factors included in the interview schedule (Chua, 2009).

A normality test was then applied to the data to examine the normal distribution of the factors, and the Kruskal-Wallis test used to explore the significant mean differences between the demographic attributes of the respondents and the newly constructed factors. The KruskalWallis test is non-parametric test of the one-factor independent ANOVA used to explore significant means differences (Carver and Nash, 2006). In this study, age, education, land size, farming experience and area under cultivation were the demographic attributes of the farmers that were tested against the factors.

\section{Results}

Field data were analysed using descriptive statistics, reliability analysis, PCA (factor analysis), normality tests and the Kruskal-Wallis test. The key findings are briefly summarised below.

\section{Descriptive statistics}

The demographic attributes of the respondents are given in Table 1. The mean farmer age was 46.5 years, but with a range between 24 and 70 years. Average schooling of respondents was approximately 7 years. Nearly a fifth (18.6\%) of respondents had no formal education.

Maximum schooling was 12 years. Respondents showed an average experience of farming of 25.3 years (minimum and maximum experience of 2 and 50 years, respectively). The average landholding size was 8.44 acres. About $3.2 \%$ of respondents were landless while $96.8 \%$ possessed land. The maximum area for ownership was 200 acres, but the average area under cultivation was 9.81 acres (minimum and maximum areas were 2 and 145 acres, respectively).

\section{Reliability analysis}

A Chronbach Alpha value of 0.723 was obtained for the 24 factors identified from the interview schedule and through a review of literature and pre-testing the research instrument. 
Kroz et al. (2008) reported that the Cronbach Alpha value should range between 0.65 and 0.75 whereas Abu and Tasir (2001) reported it should exceed 0.60 . The reliability analysis resulted in a value of $>0.65$ for this study; this confirmed the research instrument had a highreliability value.

\section{Principal Component Analysis}

Factor analysis was used on the data to identify the reasons likely to be contributing to water scarcity. The Bartlett's test of sphericity and Kaiser-Meyer-Olkin measures of sampling adequacy were used to determine matrix factorability. Bartlett's test was significant $(\mathrm{P}<0.001$, $\mathrm{p}=0.000$ ) whereas the Kaiser-Meyer-Olkin measure was 0.791, which is higher than the standard value (0.60). Coakes and Ong (2011) reported that if Bartlett's test was significant, and the Kaiser-Meyer-Olkin value is $>0.60$, then factorability is perceived to be implicit. Thus, it was considered appropriate to apply factor analysis to identify the factors contributing to farm-level water scarcity.

Table 2 shows the total variance at eight stages for the factors identified as contributing to water scarcity. Eight factors were extracted as their eigenvalues were $>1$. These explained $70.16 \%$ of the variance and were (1) rise in temperature (2) poor socio-economic condition of the farmer (3) erratic rainfall (4) warabandi (5) unequal application of water in crops (6) lesser availability of water in canals (7) uncleaned watercourses, and (8) non-adoption of highefficiency irrigation.

Table 3 shows the rotated factor matrix for the interview schedule used for farmer data collection. Tabachnick and Fidell (2001) reported that variables with loading equal to 0.45 were considered of average level whereas variables with loadings 0.32 were regarded as good. In this study, the variables all had factor loadings that were higher than 0.45 . The Varimax Rotation Method followed by Kaiser Normalization was then applied to the data. The resulting matrix showed that Factor 1 engaged eight other factors with factor loadings ranging from 0.56 to 0.84 . The factors listed in Factor 1 were f16, f21, f9, f5, f19, f4, f17 and f3. Factor 2 inducted four factors with factor loadings ranging from -0.54 to -0.83 . The factors in factor 2 were f24, f1, f12 and f8. Factor 3 consisted of three factors and loadings ranged from 0.55 to 0.79 . The factors in factor 3 were $\mathrm{f} 18, \mathrm{f} 10$ and f22. Factor 4 constituted three factors $\mathrm{f6}, \mathrm{f} 11$ and $\mathrm{f} 18$ with factors loading ranging from 0.76 to 0.78 . f13, f20 and $\mathrm{f} 14$ belonged to Factor 5 and the factors loadings ranged from 0.51 to 0.76 . Factors 6,7 and 8 each consisted of one factor, f15, f23 and f2, respectively. Factor loadings for Factor 6 were 0.54 and 0.91 for Factor 7 whereas for factor 8 loading was 0.92 .

From this analysis, 8 new factors were highlighted (Table 4). Among these, a rise in temperature received the highest variance (21.11), which meant $21.11 \%$ of its variance could be explained. The poor socio-economic condition of farmers was ranked $2^{\text {nd }}$ showing a total variance of 12.487 followed by erratic rainfall (9.05). This confirmed that the determinants of climate change had a significant contribution to water scarcity since the rise in temperature and rainfall are often denoted as strong signals of climate change. Temperature rises will speed up melting of icecaps and glaciers, whereas, erratic rainfall may cause droughts or floods which is damaging to farming communities. Warabandi, unequal application of water, less availability of canal water, uncleaned watercourses and non-adoption of high-efficiency irrigation system to conserve water were also extracted and considered strong determinants of water scarcity at farm level.

\section{Normality and Kruskal Walid tests}

The 8 factors contributing to water scarcity were then tested for normality (Table 5). Coakes and Ong (2011) confirmed that data is regarded as being normally distributed if the p-value 
for the variable being tested is $>0.05(\mathrm{P}>0.05)$. The normality test using the

Kolmogorov-Smirnov method confirmed that the normality assumption for the 8 factors didn't meet the normality assumption as the probability value was $<0.05(\mathrm{P}<0.05)$. Since the factors didn't meet the criteria for a normal distribution, a non-parametric Kruskal Walid Test was used to test the mean differences between the socio-economic attributes and the factors influencing water scarcity. These attributes included age, education, experience, landholding size of respondents and their area under cultivation. Five alternate hypotheses were tested:

1. There is a significant mean difference between the age of the respondent and the factors contributing to water scarcity;

2. There is a significant mean difference between the educational level of the respondent and the factors contributing to water scarcity;

3. There is a significant mean difference between the experience of the respondent and the factors contributing to water scarcity;

4. There is a significant mean difference between landholding size of the respondent and the factors contributing to water scarcity, and;

5. There is a significant mean difference between the area under cultivation of the respondent and the factors contributing to water scarcity.

Hypothesis 1: Table 6 shows the significant mean differences between the age of the respondents and factors such as unequal application of water in crops $(\mathrm{P}<0.05)$ and nonadoption of high-efficiency irrigation system $(\mathrm{P}<0.05)$. This implies age had an association with balanced irrigation and adoption of high-efficiency irrigation techniques. For example, young individuals can be more receptive to conserving water and improving water use efficiency. With the unit increase in age, the decision-making ability of an individual decreases. In rural settings more often older people are stereotypic and more conventional.

Hypothesis 2: Table 7 shows that the experience of a respondent had a mean difference with a rise in temperature $(\mathrm{P}<0.05)$, erratic rainfall $(\mathrm{P}<0.05)$, unequal application of water in crops $(\mathrm{P}<0.05)$, less availability of water in canal $(\mathrm{P}<0.05)$, and non-adoption of high efficiency irrigation system $(\mathrm{P}<0.05)$. This difference implies that with increasing experience respondents were more likely to observe increases in temperature and the erratic occurrence of rainfall. Similarly, farmer experience helps in recognizing to what extent balanced irrigation and adoption of high-efficiency irrigation techniques are important. In addition, respondents had experiences that were relevant to a rise in temperature including reporting on the melting of glaciers that were reducing the availability of their canal water over time.

Hypothesis 3: Table 8 shows that there was a significant mean difference in the educational level of the respondents with factors including the rise in temperature $(\mathrm{P}<0.05)$, unequal irrigation $(\mathrm{P}<0.05)$ and non-adoption of high efficiency irrigation system $(\mathrm{P}<0.05)$. For the remaining factors, the mean differences were not significant.

Hypothesis 4: Table 9 shows a significant mean difference of land holding size with the rise in temperature $(\mathrm{P}<0.05)$, Warabandi $(\mathrm{P}<0.05)$, unequal irrigation $(\mathrm{P}<0.05)$ and less availability of canal water availability $(\mathrm{P}<0.05)$. It is widely accepted that as the unit area of land increases so too does the demand for irrigation, followed by the need for adoption of techniques to conserve water. Uneven distribution of canal water limits holders of larger land areas compared to farmers with smaller land holdings. Reduced availability of canal water created more problems for the larger farms although the availability of water matters impacted on all farmers irrespective of land size and socio-economic status. The other factors showed no significant mean difference with the land holding size of the respondents. 
Hypothesis 5: Table 10 shows a significant mean difference in the area under cultivation with the reduced availability of canal water $(\mathrm{P}<0.05)$ and non-adoption of high-efficiency irrigation systems $(\mathrm{P}<0.05)$. This implies that the timely availability of canal water is critical for irrigation with reductions in crop health and yield reported to occur in response to this impact. In this context, the adoption of high-efficiency irrigation systems would help address these aspects relating to farm-level water scarcity.

\section{Discussion}

Our research focused on determining the factors which are most likely to contribute to water scarcity for agriculture. Among the 8 factors identified, a rise in temperature, poor socioeconomic conditions of the farmers, erratic rainfall, the Warabandi system, the non-uniform irrigation application, reduced availability of canal water, uncleaned water courses and nonadoption of high efficiency irrigation system were all highlighted as being most important. Factors are anthropogenic other than temperature rise and erratic rainfall. According to the Farooqi et al. (2005), rise in temperature in Pakistan could severely impact agricultural production. In Pakistan, temperature is predicted to increase by $+0.9^{\circ} \mathrm{C}$ and $+1.5^{\circ} \mathrm{C}$ by the 2020s and 2050s, respectively (Bae et al., 2015). This would negatively impact on water availability as glaciers, rainfall patterns, extreme events including droughts and floods have all shown major shifts in their long-term underlying trends. The per capita annual availability of water may also reduce, as it already has reached $<1000 \mathrm{~m}^{3}$ (Hussain and Mumtaz, 2014). Our study supports the view that a rise in temperature is likely to affect the availability of water, crop production and reduction in income generation. Farmers who are already poor in country would be poorer with the rise of temperature and fall of crop production.

The poor socio-economic conditions of the farmers studied were also shown to directly impact on agricultural water scarcity in Pakistan. Socio-economic aspects including age, education, wealth, access to information and gender do not have a direct relationship with water use per se but do have a direct association with water conservation and its judicious use. Our findings are supported by those of Darkwah et al. (2019) who reported that farm size and access to credit had a significant relationship with farmer attitudes towards water conservation. In another study by Nkegbe and Shankar (2014) it was reported that the wealth of farmers, including their land area and access to information strongly impacted on their attitudes towards adopting water conservation measures. This implies that as the socioeconomic position of farmers' increases this can lead to corresponding rises in the uptake of water conservation measures. In this study, farmers who were old, had lower levels of education and were practicing small scale farming, which collectively led towards a more likely contribution to water scarcity rather than towards water conservation.

The warabandi (canal distribution system) and unequal application of water to crops were also identified as being two important factors likely to contribute to farm-level water scarcity. As above, the poor socio-economic status of farmers combined with poor access to information means farmers are unable to adequately irrigate their crops. It is worth mentioning that excessive or reduced irrigation, both hamper impact on crop productivity. In order to meet the irrigation water requirements for their crops, farmers often use a combination of canal water and tube wells. In Pakistan, the warabandi systems are institutionalized, with a rotational distribution of irrigation allocations defined by fixed timings based on the area of land each farmer owns within the command area. The warabandi's have previously been reported to be responsible for an overall shortage of irrigation water supply (Bandaragoda and Saeed-urRehman, 1995) and the equity of water distribution depends on various factors, including conveyance losses (Iqbal and Ahmed, 2005). For example, Bhatti et al. (2017) reported high levels of efficiency in warabandi that had lined (78\%) channels compared to unlined $(50 \%)$ 
canals. A lack of canal maintenance also reduces water flows, and leads to increased seepage and evaporation losses, thus reducing the volumes available for farmers to abstract, particularly those that are situated at the downstream end of the warabandi.

Arshad et al. (2015) reported water infrastructure in Pakistan is generally poorly designed and managed resulting in significant water losses, especially during periods of irrigation. Naeem (1991) reported that one-third of the water in Pakistan is lost through conveyance. According to Anjum (1993) conveyance losses are 40\% compared to other countries where losses range between 25-50\% particularly in unlined canals (Badar, 2000). Bhatti et al. (2017) studied 15 watercourses in the Khyber Pakhtunkhwa region and estimated losses to be between 25 and $45 \%$. In contrast, Khan et al. (1999) reported a $27 \%$ increase in water delivery efficiency and $53 \%$ reduction in water losses in lined watercourses in the Khyber Pakhtunkhwa. Solangi et al. (2017) reported that water losses at field level in the Sindh region could be minimized through lining water courses. Reducing conveyance losses and increasing water availability to farmers are thus important factors in supporting increased agricultural productivity. Therefore, research institutions in Pakistan have proposed a range of techniques to combat water losses and increase water use efficiency. Farmers in Pakistan are also being provided with subsidies to strengthen their adaptive capacity. Among the different initiatives being proposed, the development of high efficiency systems including drip and sprinkler irrigation are being supported in response to persistent problems linked to water shortages in agriculture.

To increase water availability numerous efforts such as pressurised irrigation systems have been implemented in Pakistan over the last five decades, but their success has been variable (Ashraf, 2012; Yasin et al., 2001). The efficiency of drip irrigation was found to be double that of traditional surface irrigation (Latif et al., 2016). In contrast, the non-adoption of more efficient irrigation system and ongoing reliance on surface irrigation has contributed to increasing water scarcity. The efficiency of the existing tradition systems adopted by farmers in Pakistan is less than 40\% (Latif et al., 2016). This study also found that farmers had a greater inclination towards the traditional irrigation system and negligible interest in the adoption of high efficiency irrigation systems.

In different parts of Pakistan, high efficiency irrigation systems have shown positive impacts in the conservation of water, but adoption still remains very low and slow (Shah et al, 2002). Socio-economic conditions of farmers and their low levels of affordability were found to be key obstacles to the adoption of high efficiency irrigation systems. The farmer age, their level of education, land area and access to information also strongly influence the adoption of new technologies (Mango et al., 2017; Boz and Akbey, 2005). This implies that in order to expedite wider water conservation through the adoption of high efficiency irrigation system at the farm level, it will be necessary to improve the socio-economic conditions of potential beneficiaries (famers). Clearly, the poor socio-economic position of farmers in this study was a major barrier and likely to exacerbate their water access and exploitation challenges.

\section{Conclusions}

Eight factors were identified which are likely to contribute to increased water scarcity for agricultural irrigation in the Punjab region at the farm level. The Kruskal Walid test indicated that the socio-economic attributes including farmer experience, education, age, landholding and area under cultivation of the respondents all had significant mean differences with the factors linked to water scarcity. The crops grown in the study area play a vital role in contributing to rural livelihoods and the national economy. By improving the socio-economic attributes of farmers, water use efficiency can be enhanced, and ultimately this would help in reducing system level water losses and improving the uptake of water conservation measures. 
This research has highlighted how water availability and water conservation are both critically important in helping to meet future irrigation demands for Pakistan, and our findings should inform policy development and the institutions responsible for promoting sustainable development. Further research is needed to address these water security issues to ensure irrigated agriculture can deliver the required levels of productivity required in Pakistan to meet growing national demands for food and to support increased foreign exchange earnings.

\section{Acknowledgement}

This research was conducted in Faisalabad district; the authors would like to thank the Irrigation and Water Management Departments of Government of Punjab who provided data of farmers, a special thanks to Mr. Saleem Ashraf for his kind support.

\section{References}

Abu, S. and Tasir, Z., 2001. Pengenalan kepada analisis data berkomputer: SPSS 10.0 for windows. Venton.

Ahmad, M.F. and Rasul, G., 2008. Prediction of soil temperature by air temperature: A case study for Faisalabad. Pakistan Journal of Meteorology Vol5(9),.19-27.

Ahmed, A., Iftikhar, H. and Chaudhry, G.M., 2007. Water resources and conservation strategy of Pakistan. The Pakistan Development Review, 997-1009.

Alam, S.M., Ansari, S.M. and Khan, M.A., 2000. Industry and economy: Saline agriculture and Pakistan Nuclear Institute of Agriculture. Tando Jam, Pakistan.

Anjum, M.S., 1993. Marketing Constraints and Development Strategy for Edible Oils in Pakistan. USAID.

Anríquez, G. and Valdes, A., 2006. Determinants of farm revenue in Pakistan. The Pakistan Development Review, pp.281-301.

Arshad, I., Babar, M.M. and Sarki, A., 2015. Computation of Seepage Quantity in an Earthen Watercourse by SEEP/W Simulations Case Study: "1R Qaiser Minor"-Tando Jam-Pakistan. Advanced Journal of Agricultural Research 3(1), 82-88.

Asghar, S., 2014. Farming system analysis of irrigated farms in Faisalabad, Pakistan (Unpublished doctoral dissertation) CIRAD.

Ashraf, M., 2012. Overview of drip irrigation: potential, issues and constraints. Presentation in International Center for Agricultural Research in the Dry Areas (ICARDA), Pakistan on December 31 .

Awan, F. and Mustafa, U., 2013. Key factors contributing to agricultural growth in Pakistan: An application of time series analysis. Journal of Agricultural Economics and Development 1(2), 6-13.

Badar, H., 2000. Economics and sunflower production in the province of Punjab Pakistan. Unpublished M. Sc. Thesis, Department of Agri. Economics, University of Agriculture, Faisalabad.

Bae, D.H., Koike, T., Awan, J.A., Lee, M.H. and Sohn, K.H., 2015. Climate change impact assessment on water resources and susceptible zones identification in the Asian monsoon region. Water Resources Management, 29(14), 5377-5393.

Bandaragoda, D.J. and ur Rehman, S., 1995. Warabandi in Pakistan's canal irrigation systems: widening gap between theory and practice. Colombo (Sri Lanka). IIMI. 1995. 109 p (No. 96-015026. CIMMYT.). 
Bhatti, N., Qureshi, A., Solangi, G. and Panhwar, S., 2017. Effect of Watercourse Lining on Water Distribution (Warabandi) in the Command Area of Laiqpur Ex Ali Bahar Minor, District Sujawal, Sindh, Pakistan. Sindh University Research Journal-SURJ (Science Series), 49(4), pp.807-812.

Boz, I. and Akbay, C., 2005. Factors influencing the adoption of maize in Kahramanmaras province of Turkey. Agricultural Economics 33, 431-440.

Bukhari, M.H. and Sayal, E.A., 2011. Emerging climate changes and water resource situation in Pakistan. Pakistan Vision, 12(2), 236.

Burki, S.J. and Laporte Jr, R., 1984. Pakistan's development priorities. Choices for the future.

Faruqui, N.I., 2004. Responding to the water crisis in Pakistan. International Journal of Water Resources Development 20(2), 177-192.

Hussain, M. and Mumtaz, S., 2014. Climate change and managing water crisis: Pakistan's perspective. Reviews on Environmental Health 29(1-2), 71-77.

Iqbal, M. and Ahmad, M., 2005, January. Science \& Technology based Agriculture vision of Pakistan and prospects of growth. In Proceedings of the 20th Annual General Meeting Pakistan Society of Development Economics, Islamabad. Pakistan Institute of Development Economic (PIDE), Islamabad, Pakistan (pp. 1-27).

Kaleem, O., 2004. Needed a 'Blue Revolution'; National Water Policy on Anvil. The News. 8th November.

Latif, M., Haider, S.S. and Rashid, M.U., 2016. Adoption of high efficiency irrigation systems to overcome scarcity of irrigation water in Pakistan. Proceedings of the Pakistan Academy of Sciences 53, 243-252.

Lohano, H.D. and Marri, F.M., 2020. Estimating Sectoral Water Demand for Sindh Province of Pakistan. Mehran University Research Journal of Engineering and Technology 39(2), 398406.

Mango, N., Makate, C., Tamene, L., Mponela, P. and Ndengu, G., 2017. Awareness and adoption of land, soil and water conservation practices in the Chinyanja Triangle, Southern Africa. International Soil and Water Conservation Research 5(2), 122-129.

Mastoor, M., 2009. Environmental degradation: Focus on water scarcity in South Asia. Islamabad: Institute of Regional Studies.

Munir, S., 2011. Role of Sediment Transport in Operation and Maintenance of Supply and Demand Based Irrigation Canals: Application to Machai Maira Branch Canals: UNESCOIHE PhD Thesis. CRC Press.

Mustafa, D., Akhter, M. and Nasrallah, N., 2013. Understanding Pakistan's water-security nexus. Washington, DC: United States Institute of Peace.

Nabi, G., Ali, M., Khan, S. and Kumar, S., 2019. The crisis of water shortage and pollution in Pakistan: risk to public health, biodiversity, and ecosystem. Environmental Science and Pollution Research 26(11), 10443-10445.

Naeem, A., 1991. Economics of sunflower cultivation in cotton-based cropping system of the Punjab with special reference to Bahawalpur tehsil. Unpublished M. Sc. Thesis, Dept. of Agri. Econ., Univ. Agri., Faisalabad. 
Nkegbe, P.K. and Shankar, B., 2014. Adoption intensity of soil and water conservation practices by smallholders: evidence from Northern Ghana. Bio-based and Applied Economics Journal 3(1050-2016-85757), 159-174.

Peterson, S. and Klepper, G., 2007. Potential impacts of water scarcity on the world economy (pp. 263-267). Hamburg: Wissenschaftliche Auswertungen.

Ponto, J., 2015. Understanding and evaluating survey research. Journal of the Advanced Practitioner in Oncology 6(2), 168.

Qureshi, A.S., 2011. Water management in the Indus basin in Pakistan: challenges and opportunities. Mountain Research and Development 31(3), 252-260.

Rochdane, S., Reichert, B., Messouli, M., Babqiqi, A. and Khebiza, M.Y., 2012. Climate change impacts on water supply and demand in Rheraya Watershed (Morocco), with potential adaptation strategies. Water 4(1), 28-44.

Shah, T., Scott, C., Kishore, A. and Sharma, A., 2004. Energy-irrigation nexus in South Asia: Improving groundwater conservation and power sector viability (Vol. 70). IWMI.

Shehzad, M.A., Maqsood, M., Abbas, T. and Ahmad, N., 2016. Foliar boron spray for improved yield, oil quality and water use efficiency in water stressed sunflower. Sains Malaysiana 45(10), 1497-1507.

Solangi, G.S., Qureshi, A.L. and Jatoi, M.A., 2017. Impact of rising groundwater on sustainable irrigated agriculture in the command area of Gadeji Minor, Sindh, Pakistan. Mehran University Research Journal of Engineering and Technology, 36(1), pp.159-166.

Thakur, D. (2003). Research methodology in social science. Deep and Deep Publications (Pvt.) LTD. Rajouri Garden, New Dehli: 475.

Wing, E.A.S., 2019. Finance division. Government of Pakistan, "Pakistan Economic Survey", Varios números.

Yasin, M., Ahmad, S., Aslam, M. and Akbar, G., 2001, October. Adaption of pressurized irrigation in Pakistan. In Proceedings of the International Seminar on "Management of Water Resources for Sustainable Agriculture”, Lahore, Pakistan (pp. 29-31). 
Table 1. Demographic attributes of the respondents

\begin{tabular}{|l|l|l|l|}
\hline Demographic & Mean+SD & Minimum & Maximum \\
\hline Age (in years) & $46.54+12.34$ & 24 & 70 \\
\hline Education (in years) & $7.03+3.77$ & 0 & 12 \\
\hline Experience (in years) & $25.31+12.77$ & 2 & 50 \\
\hline Land owned (in acres) & $8.44+15.49$ & 0 & 200 \\
\hline Area under cultivation (in acres) & $9.81+13.58$ & 2 & 145 \\
\hline
\end{tabular}

Table 2. Total Variance of the newly constructed factors explained

\begin{tabular}{|l|l|l|l|}
\hline \multicolumn{5}{|l|}{ Rotation sums of squared loadings } \\
\hline Factors & Total & Percentage of variance & Cumulative percentage \\
\hline 1 & 5.07 & 21.12 & 21.12 \\
\hline 2 & 2.99 & 12.49 & 33.60 \\
\hline 3 & 2.17 & 9.06 & 42.66 \\
\hline 4 & 1.84 & 7.66 & 50.32 \\
\hline 5 & 1.38 & 5.74 & 56.05 \\
\hline 6 & 1.22 & 5.07 & 61.12 \\
\hline 7 & 1.14 & 4.74 & 65.86 \\
\hline 8 & 1.02 & 4.25 & 70.12 \\
\hline
\end{tabular}

Table 3. Factor matrix of the newly constructed factors

\begin{tabular}{|c|c|c|c|c|c|c|c|c|c|}
\hline \multicolumn{10}{|c|}{ Rotated Component Matrix } \\
\hline \multicolumn{2}{|c|}{ Sub-Factors } & \multicolumn{8}{|c|}{ Extracted Factors } \\
\hline & & \multirow{2}{*}{\begin{tabular}{|l|}
1 \\
.84
\end{tabular}} & \multirow{2}{*}{2} & \multirow{2}{*}{3} & \multirow{2}{*}{4} & \multirow{2}{*}{5} & \multirow{2}{*}{6} & \multirow{2}{*}{7} & 8 \\
\hline & Humidity & & & & & & & & \\
\hline & Variation in rainfall time & .79 & & & & & & & \\
\hline $\mathrm{f9}$ & Fog & .79 & & & & & & & \\
\hline $\mathrm{f5}$ & Ground water level & -.78 & & & & & & & \\
\hline f19 & Change in cropping pattern & .72 & & & & & & & \\
\hline & Effect on sowing time & .68 & & & & & & & \\
\hline $\mathrm{f} 17$ & Crop quality & .67 & & & & & & & \\
\hline & Intense farming & .56 & & & & & & & \\
\hline & Substandard livelihood & & -.83 & & & & & & \\
\hline f1 & Conflicts & & .71 & & & & & & \\
\hline & Water theft & & .63 & & & & & & \\
\hline & Kacha Khala (un-constructed water channel) & & -.54 & & & & & & \\
\hline & Germination problem & & & .79 & & & & & \\
\hline & Epidemic diseases & & & .73 & & & & & \\
\hline $\mathrm{f} 22$ & Underground water quality & & & .55 & & & & & \\
\hline & Uncleaned water courses & & & & .78 & & & & \\
\hline $\mathrm{f} 11$ & Flood irrigation & & & & 69 & & & & \\
\hline f7 & Monopoly by water distribution agencies & & & & .76 & & & & \\
\hline
\end{tabular}




\begin{tabular}{|l|l|l|l|l|l|l|l|l|l|}
\hline $\mathrm{f} 13$ & Industrialization & & & & & .58 & & & \\
\hline $\mathrm{f} 14$ & Unequal availability of water & & & & & .51 & & & \\
\hline $\mathrm{f} 20$ & Seepage and losses & & & & & .84 & & & \\
\hline $\mathrm{f} 15$ & Accumulation of mud/debris & & & & & & .54 & & \\
\hline $\mathrm{f} 23$ & Bad management of water courses & & & & & & & .91 & \\
\hline $\mathrm{f} 2$ & Poor adoptive capacity of farmer & & & & & & & & .92 \\
\hline
\end{tabular}

Table 4. Identified factors with their percentage variance

\begin{tabular}{|l|l|l|}
\hline Factors & Name & Percentage of variance \\
\hline Factor 1 & Rise in temperature & 21.12 \\
\hline Factor 2 & Poor socio-economic condition of the farmer & 12.49 \\
\hline Factor 3 & Erratic rainfall & 9.06 \\
\hline Factor 4 & Warabandi (Canal water distribution system) & 7.66 \\
\hline Factor 5 & Unequal application of water & 5.74 \\
\hline Factor 6 & Less canal water availability & 5.07 \\
\hline Factor 7 & Not cleaning of water courses & 4.74 \\
\hline Factor 8 & Non-adoption of High-efficiency irrigation system & 4.25 \\
\hline
\end{tabular}

Table 5. Normality test for the eight newly constructed factors

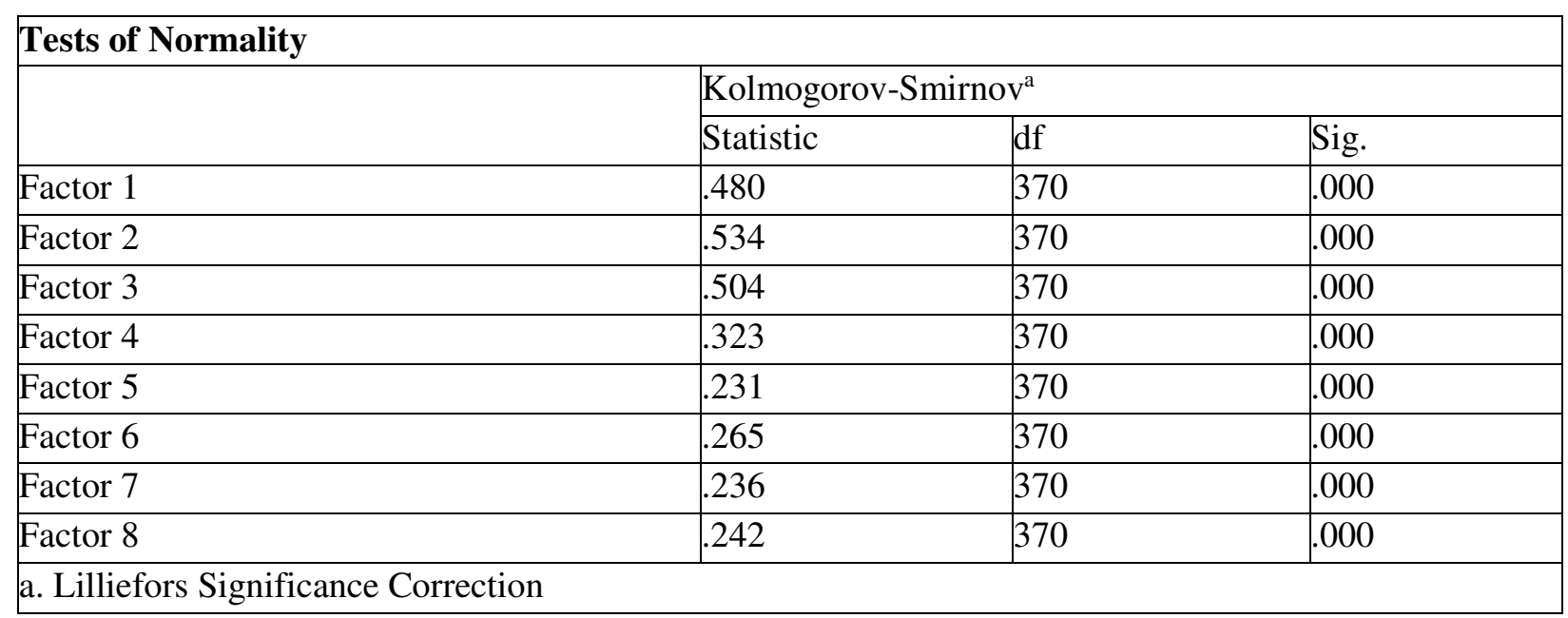


Table 6. Relationship between newly extracted factors and age of the respondents

\begin{tabular}{|l|l|l|l|}
\hline \multicolumn{2}{|l|}{ Factor } & Chi-Square & Asump Sig. \\
\hline 1 & Rise in temperature & 182.79 & 0.21 \\
\hline 2 & Poor socio-economic condition of the farmer & 159.74 & 0.10 \\
\hline 3 & Erratic rainfall & 161.35 & 0.82 \\
\hline 4 & Warabandi (Canal water distribution system) & 101.53 & 0.24 \\
\hline 5 & Unequal application of water in crops & 115.85 & 0.00 \\
\hline 6 & Less canal water availability & 114.47 & 0.13 \\
\hline 7 & Uncleaned water courses & 106.19 & 0.67 \\
\hline 8 & Non adoption of High efficiency irrigation system & 142.21 & 0.00 \\
\hline
\end{tabular}

Table 7. Relationship between newly extracted factors and experience of the respondents

\begin{tabular}{|l|l|l|l|}
\hline Factor & Chi-Square & Asump Sig. \\
\hline 1 & Rise in temperature & 151.58 & 0.030 \\
\hline 2 & Poor socio-economic condition of the farmer & 58.05 & 0.23 \\
\hline 3 & Erratic rainfall & 132.04 & 0.00 \\
\hline 4 & Warabandi (Canal water distribution system) & 72.24 & 0.78 \\
\hline 5 & Unequal application of water in crops & 86.82 & 0.00 \\
\hline 6 & Less canal water availability & 74.76 & 0.00 \\
\hline 7 & Uncleaned water courses & 95.20 & 0.41 \\
\hline 8 & Non adoption of High efficiency irrigation system & 84.96 & 0.000 \\
\hline
\end{tabular}

Table 8. Relationship between newly extracted factors and education of the respondents

\begin{tabular}{|l|l|l|l|}
\hline Factor & Chi-Square & Asump Sig. \\
\hline 1 & Rise in temperature & 12.06 & 0.020 \\
\hline 2 & Poor socio-economic condition of the farmer & 50.25 & 0.95 \\
\hline 3 & Erratic rainfall & 5.20 & 0.83 \\
\hline 4 & Warabandi (Canal water distribution system) & 31.02 & 0.10 \\
\hline 5 & Unequal application of water in crops & 11.67 & 0.00 \\
\hline 6 & Less canal water availability & 19.98 & 0.88 \\
\hline 7 & Uncleaned water courses & 32.13 & 0.43 \\
\hline 8 & Non adoption of High efficiency irrigation system & 8.40 & 0.000 \\
\hline
\end{tabular}


Table 9. Relationship between newly extracted factors and land holding size of respondents

\begin{tabular}{|l|l|l|l|}
\hline \multicolumn{2}{|l|}{ Factor } & Chi-Square & Asump Sig. \\
\hline 1 & Rise in temperature & 70.33 & 0.000 \\
\hline 2 & Poor socio-economic condition of the farmer & 92.99 & 0.13 \\
\hline 3 & Erratic rainfall & 121.45 & 0.35 \\
\hline 4 & Warabandi (Canal water distribution system) & 76.62 & 0.01 \\
\hline 5 & Unequal application of water in crops & 80.92 & 0.00 \\
\hline 6 & Less canal water availability & 84.52 & 0.00 \\
\hline 7 & Uncleaned water courses & 91.56 & 0.52 \\
\hline 8 & Non adoption of High efficiency irrigation system & 40.18 & 0.79 \\
\hline
\end{tabular}

Table 10. Relationship between newly extracted factors and area under cultivation of the respondents

\begin{tabular}{|l|l|l|l|}
\hline \multicolumn{2}{|l|}{ Factor } & Chi-Square & Asump Sig. \\
\hline 1 & Rise in temperature & 50.61 & 0.20 \\
\hline 2 & Poor socio-economic condition of the farmer & 78.03 & 0.63 \\
\hline 3 & Erratic rainfall & 109.32 & 0.15 \\
\hline 4 & Warabandi (Canal water distribution system) & 90.41 & 0.06 \\
\hline 5 & Unequal application of water in crops & 74.86 & 0.11 \\
\hline 6 & Less canal water availability & 77.18 & 0.00 \\
\hline 7 & Uncleaned water courses & 79.09 & 0.27 \\
\hline 8 & Non adoption of high efficiency irrigation system & 80.01 & 0.000 \\
\hline
\end{tabular}

